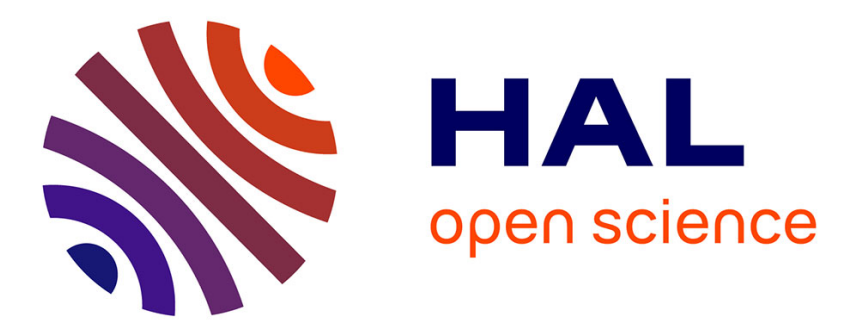

\title{
Effect-directed analysis for estrogenic compounds in a fluvial sediment sample using transgenic cyp19a1b-GFP zebrafish embryos.
}

Eva Fetter, Martin Krauss, François Brion, Olivier Kah, Stefan Scholz, Werner Brack

\section{To cite this version:}

Eva Fetter, Martin Krauss, François Brion, Olivier Kah, Stefan Scholz, et al.. Effect-directed analysis for estrogenic compounds in a fluvial sediment sample using transgenic cyp19a1b-GFP zebrafish embryos.. Aquatic Toxicology, 2014, 154, pp.221-9. 10.1016/j.aquatox.2014.05.016 . hal-01072210

HAL Id: hal-01072210

https://hal-univ-rennes1.archives-ouvertes.fr/hal-01072210

Submitted on 7 Oct 2014

HAL is a multi-disciplinary open access archive for the deposit and dissemination of scientific research documents, whether they are published or not. The documents may come from teaching and research institutions in France or abroad, or from public or private research centers.
L'archive ouverte pluridisciplinaire HAL, est destinée au dépôt et à la diffusion de documents scientifiques de niveau recherche, publiés ou non, émanant des établissements d'enseignement et de recherche français ou étrangers, des laboratoires publics ou privés. 


\section{Effect-directed analysis for estrogenic compounds in a fluvial sediment sample using} transgenic cyp19a1b-GFP zebrafish embryos

Eva Fetter ${ }^{1}$, Martin Krauss ${ }^{2}$, François Brion ${ }^{3}$, Olivier Kah ${ }^{4}$, Stefan Scholz ${ }^{1}$, Werner Brack ${ }^{2}$,

${ }^{1}$ Department of Bioanalytical Ecotoxicology, Helmholtz Centre for Environmental Research

- UFZ, Permoserstraße 15, 04318 Leipzig, Germany

${ }^{2}$ Department of Effect-Directed Analysis, Helmholtz Centre for Environmental Research UFZ, Permoserstraße 15, 04318 Leipzig, Germany

${ }^{3}$ Unité d'écotoxicologie in vitro et in vivo, Direction des Risques Chroniques, Institut National de l'Environnement Industriel et des Risques (INERIS), BP 2, F-60550 Verneuil-enHalatte, France

${ }^{4}$ Research Institute for Environment, Health and Occupation, INSERM U1085, Biosit, Université de Rennes 1, Campus de Beaulieu, 35042 Rennes cedex, France

Corresponding author: Eva Fetter

Email: eva.fetter@ufz.de

Tel: +49 3412351509

Fax: +49 3412351787 


\begin{abstract}
Xenoestrogens may persist in the environment by binding to sediments or suspended particulate matter serving as long-term reservoir and source of exposure, particularly for organisms living in or in contact with sediments. In this study, we present for the first time an effect-directed analysis (EDA) for identifying estrogenic compounds in a sediment sample using embryos of a transgenic reporter fish strain. In the $\operatorname{tg}($ cyp19a1b-GFP) transgenic zebrafish strain, the expression of GFP (green fluorescent protein) in the brain is driven by an estrogen responsive element in the promoter of the cyp19a1b (aromatase) gene. The selected sediment sample of the Czech river Bilina had already been analysed in a previous EDA using the yeast estrogen screening assay and had revealed fractions containing estrogenic compounds. When normal phase HPLC (high performance liquid chromatography) fractionation was used for the separation of the sediment sample, the biotest with transgenic fish embryos revealed two estrogenic fractions. Chemical analysis of candidate compounds in these sediment fractions suggested alkylphenols and estrone as candidate compounds responsible for the observed estrogenic effect. Alkylphenol concentrations could partially explain the estrogenicity of the fractions. However, xenoestrogens below the analytical detection limit or non-targeted estrogenic compounds have probably also contributed to the sample's estrogenic potency. The results indicated the suitability of the $\operatorname{tg}(\operatorname{cyp} 19 a 1 b$-GFP) fish embryo for an integrated chemical-biological analysis of estrogenic effects.
\end{abstract}

Keywords: endocrine disruptors; environmental xenoestrogens; animal alternatives; Danio rerio; aromatase; fractionation 


\section{Introduction}

Numerous studies have shown that a large number of manmade chemicals represent potential estrogen receptor (ER) agonists (Colborn et al., 1993; Frye et al., 2012; Maffini et al., 2006) capable to activate estrogen signalling pathways thus interfering with estrogen-regulated processes. In the aquatic environment these chemicals are of high concern due to their interference with sexual differentiation and reproduction in fish and other aquatic vertebrates (Kidd et al., 2007; Scholz and Klüver, 2009). Effluents from wastewater treatment plants, sewage discharges and stormwater runoff from rural areas represent major sources of these xenoestrogens (Nakada et al., 2006; Racz and Goel, 2010; Yang et al., 2012). Ultimately they can also accumulate in sediments since many xenoestrogens are moderately hydrophobic with a $\log \mathrm{K}_{\mathrm{ow}}$ (octanol-water partition coefficients) typically in the range of 3-5 (Racz and Goel, 2010). Thus, they provide a source of continuous exposure for aquatic organism (via sediment contact or through desorption into the water column).

Many estrogenic compounds in the aquatic ecosystems are typically present at or even below the analytical detection limit. However, even these low concentrations can be of biological relevance given the potential combined effect of estrogen agonists (Silva et al., 2002). Thus, effect-based monitoring approaches play a key role in the detection of estrogens in the environment. However, the detection of estrogenicity by biological test systems is often hampered by the complexity of environmental mixtures. Toxic components may mask the estrogenic response (Hollert et al., 2005). One of the approaches to address this challenge is the application of effect-directed analysis (EDA), an approach that applies fractionation techniques together with biotesting in order to reduce sample complexity, to make masked effects detectable and to support the identification of causative chemicals (Brack, 2003). There are numerous studies reporting the use of in vitro assays to assess estrogenicity of riverine sediment samples (Grund et al., 2011; Schmitt et al., 2012; Wang et al., 2012). The use of such in vitro assays in EDA approach has been shown relevant in identifying environmental ligands of steroid receptors including ER (Creusot et al., 2014; Creusot et al., 2013). However, in vitro assays cannot reflect the complexity of an organism due to limitations of pharmacokinetic and pharmacodynamic processes. Vertebrates are difficult to use for EDA approaches, because of ethical reasons, the limited number of sample material, and the high sample numbers to analyse. However, the use of embryos of zebrafish (Danio rerio) provides an alternative to experiments with adult animals. In contrast to cellular in vitro models, the use of fish embryos combines the complexity of a full organism with the simplicity and reproducibility of cellular assays. Zebrafish embryos have been already shown 
to be compliant with the EDA approach as reported in a study on developmental toxicants in soil sample from a municipal landfill site (Legler et al., 2011).

For the assessment of estrogenic activity, alterations in expression of estrogen-regulated genes are frequently used as end-points (Jung et al., 2012). In transgenic zebrafish strains, quantification of estrogen-sensitive genes is facilitated by fluorescence or luminescence of reporter genes (Brion et al., 2012; Chen et al., 2010; Ji et al., 2012; Legler et al., 2000). Recently, embryos of the $\operatorname{tg}(c y p 19 a 1 b$-GFP) strain have been successfully used for the assessment of the estrogenic activity of synthetic or natural hormones, industrial chemicals and mixtures of these (Brion et al., 2012; Petersen et al., 2013). This transgenic strain contains a construct of the promoter region of the ER-regulated zebrafish brain aromatase gene (cyp19a1b) linked to green fluorescent protein (GFP). The brain aromatase is responsible for the conversion of androgens to estrogens and its expression is restricted to the radial glial cells (Menuet et al., 2005). GFP expression in the $\operatorname{tg}($ cyp19a1b-GFP) strain perfectly mimics the expression of the endogenous cyp19a1b (Tong et al., 2009; Vosges et al., 2010). It has been shown that the estrogenic regulation of the cyp19a1b requires estrogen-responsive element (ERE and 1/2 ERE) and a glial x-responsive element (GxRE) recruiting glial-specific transcription factors (Le Page et al., 2008; Menuet et al., 2005). This results in a high brainspecific upregulation of the cyp19a1b gene in fish (especially in embryos) exposed to agonist ligands of ER or compounds that are metabolized into estrogenic metabolites (e.g., proestrogenic compounds, aromatisable and non -aromatisable androgens) (Brion et al., 2012; Mouriec et al., 2009).

In this study, we present the first application of the $\operatorname{tg}($ cyp19a1b-GFP) embryos for the assessment of the estrogenic activity in the EDA of an environmental sample. EDA was conducted on the extract of a sediment sample from the Czech river Bilina, for which a previous analysis (Schmitt et al., 2010) using the yeast estrogen screening assay (YES) had identified estrogenic effects. Given the known estrogenic activity of this sediment sample it was used as a proof-of-principle to evaluate the suitability of embryos of a transgenic zebrafish reporter strain for the identification of estrogenic effects and compounds in sediments by EDA.

\section{Materials and methods}

\subsection{Chemicals}

A list of suppliers of analytical standards, chemicals and corresponding CAS number used during the exposure experiments can be found in the Table S1. 


\subsection{Effect-directed analysis}

\subsubsection{Sediment sampling}

The sediment sample was obtained from a sampling campaign at the city of Most from the river Bilina, Czech Republic. Further details about the site and the sample processing were already described by Schmitt et al. (2010).

\subsubsection{Sample preparation}

Chemicals from the sediment sample were extracted with pressurized liquid extraction, followed by a clean-up with gel permeation chromatography and fractionation with normal phase HPLC. In each step of sample preparation an aliquot of the sample was removed and analysed for the presence of estrogenic compounds using embryos of the $\operatorname{tg}(\operatorname{cyp} 19 a 1 b$-GFP) zebrafish strain. Prior to analysis of estrogenic effects, aliquots had been exposed to different dilutions (see below) to identify the highest non-toxic concentration. Toxicity tests had been performed as described by Knöbel et al. (2012) except that exposures were conducted in crystallization dishes. In those aliquots where no lethal or sublethal effect was shown, the estrogen screening assay was performed (see Fig. 1).

\section{Pressurized liquid extraction}

Fifty grams of the sediment sample were subjected to pressurized liquid extraction (PLE) in an accelerated solvent extraction (ASE) apparatus (Dionex ASE 200 Idstein, Germany). In brief, the sample was split up into portions of $10 \mathrm{~g}$ and mixed thoroughly with 4.2-4.5 $\mathrm{g}$ of anhydrous $\mathrm{Na}_{2} \mathrm{SO}_{4}$, filled into a $33 \mathrm{~mL}$ stainless steel extraction cell and extracted with acetone and dichloromethane (DCM) (35:65 volume ratio) at a temperature of $50^{\circ} \mathrm{C}$ and a pressure of 1,500 psi. The extraction was performed in three cycles of static extraction for 10 min. Finally, the extraction cell was purged for $100 \mathrm{~s}$ with nitrogen. From the total extraction volume of $450 \mathrm{~mL}$ corresponding to $50 \mathrm{~g}$ sediment equivalents (SEQ), an aliquot of $10 \mathrm{~mL}$, corresponding to $1.1 \mathrm{~g}$ SEQ was removed, dried under nitrogen and redissolved in $1.5 \mathrm{~mL}$ of dimethylsulfoxide (DMSO). Fish embryos were exposed to dilutions of $0.01,0.1$ and $1 \%$ of this DMSO sediment extract. Since malformations and oedema were observed for $>20 \%$ of all embryos in the $1 \%$ dilution, we did not analysed estrogenic activity for this concentration. The remaining $440 \mathrm{~mL}$ (48.9 SEQ) from the initial PLE extract were concentrated and redissolved in $10 \mathrm{~mL}$ of DCM for further extraction by gel permeation (Fig. 1).

\section{Gel permeation chromatography clean-up}


The sediment extract was subjected to a clean-up by gel permeation chromatography (GPC) in order to eliminate macromolecules (e.g. humic acid) and elemental sulfur. The clean-up method was conducted according to the EPA 3640 test method using a Bio-Beads S-X3 gel column with a DCM (5 mL/min) mobile phase (EPA, 1994). The injection volume was $1 \mathrm{~mL}$ and the collection window was set to 22.2-45.5 $\mathrm{min}$ (of $66 \mathrm{~min}$ total duration). The collected fractions from the subsequent runs were poured together, dried under nitrogen and redissolved in $10 \mathrm{~mL}$ of $\mathrm{n}$-hexane. One $\mathrm{mL}$ of $\mathrm{n}$-hexane extract was dried in a gentle stream of nitrogen and redissolved in $1 \mathrm{~mL}$ of DMSO which corresponds to 4.89 SEQ. Dilutions of $0.01,0.05 \%$ of this cleaned-up extract was used for analysis of estrogenic activity, since dilutions of 0.1 , 0.5 and $1 \%$ caused mortality.

\section{Normal-phase HPLC fractionation}

Extracts corresponding to $44.01 \mathrm{~g}$ SEQ were loaded onto a HPLC by two consecutive injections of $4.5 \mathrm{~mL}$. HPLC fractionation composed of three solvent delivery modules (Pro Star 210, Varian, Palo Alto, CA, USA), a fraction collector (Pro Star fraction collector 701, Varian), and a diode array detection system (Pro Star PDA detector 330, Varian) operated from 200 to $400 \mathrm{~nm}$. For the fractionation a stainless steel cyanopropyl silica column (VP 125/21 Nucleosil 100-5 CN, Macherey and Nagel, Düren, Germany) was used. A flow of $10 \mathrm{~mL} / \mathrm{min}$ was applied with $100 \% \mathrm{n}$-hexane for $17 \mathrm{~min}$, followed by a linear gradient to $100 \%$ of DCM within 10 min and then by a linear gradient to $100 \%$ of acetonitrile within 20 min, which was held for ten minutes followed by a re-equilibration. The fractions were collected at ten retention time intervals: 0-14:00, 14:01-19:00, 19:01-23:00, 23:01-27:00, 27:01-31:00, 31:01-35:00, 35:01-39:00, 39:01-43:00, 43:01-47:00 and 47:01-51:00. The resulting fractions were collected from the two runs, united, dried in a stream of nitrogen and redissolved in $10 \mathrm{~mL}$ of $\mathrm{n}$-hexane. For testing of estrogenic activity $7.5 \mathrm{~mL}$ (corresponding to 33 g SEQ) were removed, dried again under a gently stream of nitrogen and redissolved in 1 $\mathrm{mL}$ of DMSO. The intermediate step of dilution in hexane was conducted to ensure equal treatment of samples for chemical analysis and bioassays. Dilutions of $0.01,0.05$ and $0.1 \%$ of fractions dissolved in DMSO were assessed for toxicity. The highest sublethal concentrations $(0.01 \%$ of fraction 1,5 , and $9 ; 0.05 \%$ of all other fractions) were used for analysis of estrogenic effects in zebrafish embryos. The remaining $2.5 \mathrm{~mL}$ (11.01 SEQ) of the fractions in n-hexane were used for target analysis of selected chemicals. 


\subsubsection{Analysis of selected compounds with GC-MS}

GC-electron ionization-MS analysis was performed to identify selected potential estrogenic compounds in the fractions. One $\mathrm{mL}$ of each $2.5 \mathrm{~mL}$ fraction was concentrated in $200 \mu \mathrm{L}$ of hexane and screened for musk compounds. Aliquots of $400 \mu \mathrm{L}$ of each fraction were concentrated in $50 \mu \mathrm{L}$ of hexane and used for analysis of steroids and alkylphenols after derivatisation. An Agilent 6890 GC coupled to an Agilent 5973 mass spectrometer equipped with a DB-5ms fused silica capillary column (Agilent) and an Agilent 7683 Series Autosampler were used. Helium was used as carrier gas at a constant flow of $1.2 \mathrm{~mL} / \mathrm{min}$. A volume of $1 \mu \mathrm{L}$ of sample was injected using splitless mode at $280^{\circ} \mathrm{C}$ injector temperature. The oven temperature program was as follows: $60-150{ }^{\circ} \mathrm{C}$ at an increment of $30{ }^{\circ} \mathrm{C} / \mathrm{min}$, increase to $186^{\circ} \mathrm{C}$ at an increment of $6^{\circ} \mathrm{C} / \mathrm{min}$, followed by an increment of $4^{\circ} \mathrm{C} / \mathrm{min}$ to $280^{\circ} \mathrm{C}$ and final incubation for $16.5 \mathrm{~min}$ at $280^{\circ} \mathrm{C}$. The mass spectrometer was operated either in full scan mode or in the selected ion monitoring (SIM) mode. Prior to the analysis of steroids and alkylphenoles by GC-MS, a silyation with N-Methyl-N-(trimethylsilyl) trifluoroacetamide (MSTFA) and ammonium iodide as catalyst was carried out. As reduction agent mercaptoethanol was added to the derivatisation reaction mixture, which was then held at $65^{\circ} \mathrm{C}$ for ten minutes. The ratio of MSTFA: mercaptoethanol: ammonium iodide was set to 99.1: 0.5: 0.4 .

To confirm the detected steroids and alkylphenols and analyse additional compounds, the fractions were reanalysed using a different derivatisation procedure and a more sensitive and selective GC-MS/MS method on an Agilent 7890 GC coupled to an Agilent 7000 triple quadrupol mass spectrometer. The derivatisation procedure was based on Andrási et al. (2011) and included a conversion of keto groups to the corresponding oximes using $50 \mu \mathrm{L}$ of $25 \mathrm{mg} / \mathrm{mL}$ hydroxylamine hydrochloride in pyridine $\left(30 \mathrm{~min}\right.$ at $\left.70^{\circ} \mathrm{C}\right)$ followed by silylation of hydroxy and oxime groups with $135 \mu \mathrm{L}$ hexamethyldisilazane / $15 \mu \mathrm{L}$ trifluoroacetic acid $\left(180 \mathrm{~min}\right.$ at $\left.70^{\circ} \mathrm{C}\right)$. GC conditions were as described above. Derivatives were analysed after electron ionization in multiple reaction monitoring mode with up to three transitions per compound.

\subsection{Screening for estrogenic activity using tg(cyp19a1b-GFP) zebrafish embryos}

\subsubsection{Zebrafish maintenance and exposure of embryos}

The $\operatorname{tg}($ cyp19a1b-GFP) zebrafish strain (Tong et al., 2009) generation F4 was obtained from Université de Rennes 1 (Research Institute for Environment, Health and Occupation, INSERM U1085, Biosit, Rennes, France) and from INERIS. Initially, we observed a relatively high background of malformations in this strain. Therefore, we crossed this strain 
with the UFZ-OBI wild type strain, which has been established from a stock of a local breeder and kept for several generations at the UFZ. Offspring and subsequent generations had a very low level of malformations similar to wild type strains $(<10 \%)$. For maintenance of the transgenic strain, the GFP positive embryos (identified by constitutive GFP expression in the brain) were raised to adults and the embryos of this generation were used in this study. Due to this selection of transgenic offspring during several generations an unknown degree of nontransgenic, hetero- and homozygous individuals was reached. However, non-transgenic embryos can be identified by a lack of a weak constitutive GFP-expression and were excluded from the analysis of estrogenic effects. Fish were cultured at $26 \pm 1{ }^{\circ} \mathrm{C}$ at a $14: 10 \mathrm{~h}$ light: dark cycle in a recirculating tank system according to standard procedures (Westerfield, 1993).

In order to validate the sensitivity and reproducibility of GFP induction of the cyp19a1b-GFP strain, embryos were exposed to a series of concentrations of $17 \alpha$-ethinylestradiol (EE2) and two weak non-steroidal estrogenic compounds, bisphenol A (BPA) and the technical mixture of nonylphenols (NP). $\mathrm{EC}_{50}$ concentrations of all compounds were similar to the values described by Brion et al. (2012) and Petersen et al. (2013) (Fig. S1).

Transgenic zebrafish embryos were exposed from 2 hours to 5 days post fertilisation (dpf) to $0.01-1 \%(\mathrm{v} / \mathrm{v})$ dilutions of sediment extracts and fractions in embryonic medium (294.0 $\mathrm{mg} / \mathrm{L} \mathrm{CaCl} 2 \cdot 2 \mathrm{H}_{2} \mathrm{O}, 123.3 \mathrm{mg} / \mathrm{L} \mathrm{MgSO}_{4} \cdot 7 \mathrm{H}_{2} \mathrm{O}, 64.7 \mathrm{mg} / \mathrm{L} \mathrm{NaHCO}_{3}$ and $\left.5.7 \mathrm{mg} / \mathrm{L} \mathrm{KCl}\right)$. Exposure of embryos to $0.05-1 \%$ (v/v) DMSO (corresponding to the highest solvent concentration in sediment extract tested in an experiment) served as solvent control. DMSO concentrations $(\leq 1 \%)$ did not exceed levels previously shown to be tolerated by zebrafish embryos (Ali et al., 2011; Maes et al., 2012). As a positive control, exposure to 50 pM EE2 (nominal concentration) was used. The stock of EE2 $(1 \mu \mathrm{M})$ was prepared in DMSO and kept at $4{ }^{\circ} \mathrm{C}$. For the validation experiments, stocks of coprostanol (saturated) and NP $(1 \mathrm{mM})$ were prepared in DMSO. Dilutions of the stock were prepared freshly before starting the exposure. Each experimental group was tested using 25-30 embryos exposed in $25 \mathrm{~mL}$ in crystallization dishes. Embryos were kept in an incubator until $5 \mathrm{dpf}$ at $26^{\circ} \mathrm{C}$ with complete daily renewal of the exposure media. $5 \mathrm{dpf}$ embryos were analysed for toxicity and teratogenicity prior to the analysis of the GFP fluorescence. Lethality was identified by coagulation, missing heartbeat, a non-detached tail and missing of somites as described by (Nagel, 2002). Hatching rate was analysed as a sub-lethal toxicity indicator. Malformations such as oedema and body curvature were used as indicator of teratogenicity. In case that frequency of normal development was $\geq 80 \%$, GFP fluorescence was analysed. 
All zebrafish husbandry and experimental procedures were performed in accordance with the German animal protection standards and were approved by the Government of Saxony, Landesdirektion Leipzig, Germany (Aktenzeichen 75-9185.64). According to the Guidelines on the protection of experimental animals by the Council of Europe, Directive 2010/63/EU, zebrafish embryos up to the stage of independent feeding (approximately 5 days after fertilization) can be considered as alternatives to animal testing and could be used without the need for animal testing licensing (Strähle et al., 2012).

\subsubsection{Quantification of GFP induction in tg(cyp19a1b-GFP) zebrafish embryos}

The analysis of fluorescence in the brain region of $\operatorname{tg}($ cyp19a1b-GFP) zebrafish embryos was performed according to Brion et al. (2012) with small modification. In brief, $5 \mathrm{dpf}$ embryos were anesthetized with MS222 mounted in 5\% methylcellulose on microscope slides with dorsal side to the bottom. At least 10 embryo per sample were photographed using the same illumination conditions with a Leica 4000 DMI inverse microscope equipped with a Leica digital camera DFC 350FX. The micrographs were then analysed using the Image J software (http://rsbweb.nih.gov/ij/). For each picture, the integrated pixel density was measured, i.e. the sum of the grey-values of all the pixels within the region of interest. A grey-value of 45 (maximum grey value 255) was defined as background value and used to identify the region of interest excluding pixels having grey values below this threshold. For each micrograph a fold induction of fluorescence was calculated comparing the integrated pixel density with that of the mean of the controls. The analysis was run in triplicates.

Statistical data analysis was performed only on the fractionated samples with IBM SPSS (version 22) using the mean fold change of the ten imaged embryo for each fraction. Normality and homoscedasticity of the data was checked with the Shapiro-Wilk and the Levene's test, respectively using the natural log transformed fold change data. As the data were normally distributed and homoscedastic, one-way ANOVA using Dunnet's post-hoc test was applied to identify significantly different effects of treatments from control.

\subsubsection{Confirmation of the findings of the $\operatorname{tg}($ cyp19a1b-GFP) zebrafish embryo test with real- time qPCR}

In order to confirm the induction of cyp19a1b aromatase revealed by GFP fluorescence in the transgenic strain, total RNA was extracted from 25 randomly selected control or exposed zebrafish embryos at 5 dpf. $2 \mu \mathrm{g}$ of total RNA was reversely transcribed with RevertAid ${ }^{\mathrm{TM}} \mathrm{H}$ Minus Reverse Transcriptase (Fermentas, Leon-Roth, Germany) in $20 \mu \mathrm{L}$ reaction mix according to the manufacturer instructions. qPCR was carried out using a Step-One-Plus PCR System (Applied Biosystems, Darmstadt, Germany) and SensiMix ${ }^{\mathrm{TM}}$ SYBR with ROX as 
passive reference dye (Bioline, Luckenwalde, Germany) in $12.5 \mu \mathrm{L}$ reaction volume. As housekeeping gene for normalisation of cyp19a1b expression, glyceraldehyde 3-phosphate dehydrogenase (gapdh) was used. The qPCR was performed on samples from three independent experiments using the following primers: 5'-GATACACGGAGCACCAGGTT3' and 5'-GCCATCAGGTCACATACACG-3' for gapdh (product length: 163 bp); 5'GCTCCAGACACGCTCTCCAT-3' and 5'-CATCCTCCAGAGACTGCCTCA-3' for cyp19a1b (product length: $223 \mathrm{bp}$ ). The PCR reaction was conducted with an initial denaturation of $10 \mathrm{~min}$ at $95^{\circ} \mathrm{C}$, followed by 45 cycles of $15 \mathrm{~s}$ denaturation at $95^{\circ} \mathrm{C}, 20 \mathrm{~s}$ annealing at $57^{\circ} \mathrm{C}$ and $20 \mathrm{~s}$ elongation at $72^{\circ} \mathrm{C}$. Melting curve analysis was conducted to ensure the gene specificity of the primers. Relative expression levels were determined by using the $\Delta \Delta \mathrm{Ct}$ method (Pfaffl, 2001).

\section{Results}

\subsection{Estrogenic activity of the sediment fractions}

After each step of sample preparation, $\operatorname{tg}(c y p 19 a 1 b$-GFP) zebrafish embryos were exposed to an aliquot of the extracts. Prior to analysis of estrogenic activity, the non-toxic dilutions of sediment extracts were identified by analysis of teratogenicity and toxicity in a dilution series of the sample aliquots. The highest non-toxic dilution was then used for analysis of GFP fluorescence.

Exposing the embryos to the extract directly obtained after the pressurized liquid extraction resulted in the highest toxicity. The dilutions showing no malformations among embryos referred to 73 and $730 \mathrm{mg}$ SEQ/L. No estrogenic effects could be observed for these concentrations (Fig. 2, A).

After GPC, the extract did not exhibit any toxicity up to $2.45 \mathrm{~g} \mathrm{SEQ/L}$. Also for this concentration, no GFP induction was observed (Fig. 2, B).

After the HPLC fractionation, toxicity and estrogenicity of individual fractions were assessed in 5 dpf embryos. The highest non-toxic dilutions of fractions (F) F1, F5, and F9 corresponded to $3.3 \mathrm{~g} \mathrm{SEQ} / \mathrm{L}$, for all other fractions to $16.5 \mathrm{~g} \mathrm{SEQ} / 1$. A precipitate could be observed when the embryos were exposed to F6. Fractions of higher polarity (F6-F8 and F10) exhibited the highest estrogenic activity with 7.92, 3.25, 5.13 and 2.33 fold induction above the solvent control, respectively. Relative expression of the cyp191b gene revealed similar fold induction values (12.1, 2.4, 4.2 and 6.3, respectively) (Fig. 3).

The analysis of $\operatorname{tg}($ cyp19a1b-GFP) zebrafish embryos were repeated in a second laboratory (François Brion, INERIS, France) in two independent experiments using similar exposure and evaluation protocols (see Fig. S2 for details). The estrogenicity of the fraction F6 could be 
confirmed, although lower fold induction in fraction F6 (2.63) and in the positive control, 50 pM EE2 (10.71) were observed.

\subsection{Target analysis in the sediment extract fractions}

A set of 35 different compounds including known estrogenic compounds, steroids and sterols were analysed in ten fractions of the Bilina sediment sample (Table 1). Estrogenic or potentially estrogenic compounds were detected in fraction F4 - F10. A few musks were present at relatively low concentrations particularly in the fractions F4-F5. Among these, tonalide, amberonne, benzophenone and methyl cedryl ketone were found in concentrations ranging from 18-69 ng/g. Also low levels of BPA were detected in these fractions. In F6, NP $-260 \mathrm{ng} / \mathrm{g}(1.2 \mathrm{nmol} / \mathrm{g})$ and coprostanol $-63.1 \mu \mathrm{g} / \mathrm{g}(162.4 \mathrm{nmol} / \mathrm{g})$ were the two most highly abundant compounds. Other compounds could not be detected or were found only in low amounts, such as the estrogenic octylphenol $(7.1 \mathrm{ng} / \mathrm{g}$ or $34.4 \mathrm{pmol} / \mathrm{g})$.

In fraction F7 to F10, which represented the more polar fractions, particularly estrone and the sterols coprostanol, $\beta$ sitosterol and cholesterol have been found in concentrations up to 0.70 $1.7,11.1$ and $17.8 \mu \mathrm{g} / \mathrm{g}(2.6,4.3,26.9$, and $46.0 \mathrm{nmol} / \mathrm{g})$, respectively. Gestagens or synthetic estrogens were not detected in any of the fractions.

\subsection{Estrogenic activity of coprostanol}

No information on estrogenic effects in fish embryos or other test system was available for coprostanol, the compound that was present in the highest concentration in the sediment fractions. Coprostanol is a very hydrophobic compound with a very low water solubility (Clements, 1994) (Table 2). To exclude this compound as the cause of the measured effect we tested coprostanol for estrogenic effects in saturated solution and at a nominal concentration of $2.7 \mu \mathrm{M}$ (referring to concentrations in the sediment). A strong precipitation in the exposure medium and no GFP induction were observed.

\section{Discussion}

Chemical analysis alone is not appropriate for ecotoxicological hazard assessment, as it is unable to assess compounds below the analytical detection limit or chemicals of which toxic effect has not been a priori identified. Furthermore, global effects of chemicals such as interaction among them cannot be assessed using chemical analysis. EDA helps to reveal the link between adverse effect and causative chemicals (Brack, 2003). In this study, an EDA for estrogenic samples was applied for the first time using embryos of a transgenic zebrafish. Transgenic strains with fluorescent reporters benefit from the possibility of continuous analysis and minimal sample processing. This means that the biological effect can be 
quantified in living embryos directly from the observation of reporter gene fluorescence, enabling a relative short, simple and automatable screening of environmental samples (PardoMartin et al., 2010). Cellular in vitro reporter gene assays principally provide a faster and easier quantifiable tool for estrogen receptor transactivation. In contrast, the zebrafish embryo represents a complex model system more closely related to an adult animal and with potentially more similar toxicokinetic properties and metabolizing capacities. For instance, it allows detecting also aromatisable androgens, converted by the brain aromatase (Brion et al., 2012; Mouriec et al., 2009). Furthermore, estrogenic effects can be analysed in the context of other endpoints such as e.g. teratogenicity, neurotoxicity or other endocrine endpoints (Scholz, 2013). Higher tier approaches such as the use of 21-day screening assays (OECD, 2009; USEPA, 2009) may provide an integration of additional mechanisms for various mode of action leading to endocrine disruption. However, these assays are not feasible for an EDA approach given the need for large sample volumes and prolonged exposure. Similarly, more global approaches such as transcriptome analysis (Quesada-Garcia et al., 2013; Wang et al., 2008) are not feasible for EDA, given the large sample number, high costs and significant demand for multivariate data analysis.

The aim of this study was to investigate the principal suitability of transgenic zebrafish embryos by application of the $\operatorname{tg}($ cyp19a1b-GFP) line for analysis of a sediment sample from the Czech river Bilina. The YES assay has indicated the presence of estrogenic compounds for this sample in a previous EDA (Schmitt et al., 2010). The sample was selected in order to prove the applicability of transgenic fish in general and specifically of the $\operatorname{tg}(\operatorname{cyp} 19 a 1 b$-GFP) zebrafish embryo, not for a comparative assessment of both assays.

4.1 Clean-up and fractionation increased the maximum tolerable concentration of sediment extracts and led to the detection of estrogenic effect in zebrafish embryos

Assessing estrogenic and/or endocrine disrupting effects in environmental samples is often a challenge due to the complexity of the sample. The estrogenic activity of a sample can be masked by the presence of toxic substances (Frische et al., 2009). Sample dilution would reduce the level of confounding toxic compounds but also the concentration of potential estrogen agonists. According to the mortality analysis with zebrafish embryos, the maximum tolerable concentration of sediment was indeed increased by gel permeation and the subsequent fractionation based on SEQ estimation. Furthermore, significant estrogenic effects could be identified only after fractionation and were found in the more polar fractions F6 and F8. Since most of the known estrogen agonists are relatively polar compounds, estrogenic activity could be expected particularly for these fractions (Rastall et al., 2006). 
By analysis of aromatase expression by qRT-PCR, similar fold induction rates were obtained, confirming that GFP fluorescence indeed was representing the brain aromatase expression as has also been previously shown for individual compounds by Brion et al. (2012).

4.2 Different compounds are suggested as candidate compounds for estrogenic effects of the Bilina sediment by two independent studies

The catchment of the river Bilina in the Elbe basin is one of the most heavily impacted areas in Central Europe due to former mining activities, chemical and petrol industry (Orendt et al., 2012). After the political changes in 1990, industrial activities and discharge of effluents along the river declined resulting in an improved water quality according to chemical analysis. However, the ecological status did not recover (Jurajda et al., 2010). This may have many reasons and could partially also be due to exposure of organism to pollutants via sediments and the food chain.

Apart from the industrial discharges, the Bilina catchment also receives effluents of municipal wastewater from different cities (Jirkov, Litvinov and Most). This was confirmed by the identification of various sterols such as cholesterol and coprostanol in the sediment fractions. These sterols are usually analysed as tracers for contaminations by municipal effluents, since they derive from human faeces (Marvin et al., 2001).

The sediment sample that was selected for conducting an EDA of estrogenic effects using the $\operatorname{tg}($ cyp19a1b-GFP), was retrieved from a location at the city of Most downstream of the discharge of municipal wastewater. Previous analysis of a non-fractionated extract of this sediment with the YES assay has revealed an estrogenic activity (Schmitt et al., 2010), whereas chemical analysis revealed concentrations of all measured steroid estrogens below the detection limits. Xeno-estrogenic alkylphenols (NP) were detected at concentrations up to $0.001 \mathrm{ng} / \mathrm{g}$ sediment. Ethoxylated NP was detected in higher concentrations $(0.14 \mathrm{ng} / \mathrm{g}$ sediment for 4-NP di-ethoxylate). Given these low concentrations it was unlikely that either steroids or alkylphenols contributed to the estrogenic activity.

Our study did only reveal estrogenic effects after a fractionation using NP-HPLC. Two out of 10 fractions significantly induced GFP fluorescence. Comparison of measured concentrations of the selected compounds between estrogenic and non-estrogenic fractions suggested alkylphenols and the natural steroid estrone as candidate compounds to be responsible for the estrogenic effects in F6 or F8, respectively. 
4.3 Compounds identified in the estrogenic fractions F6 and F8 could not fully explain the estrogenic effects of fractions

For F6, two compounds with known estrogenic activity, 4-tert-octylphenol (OP) and NP were identified. NP is known to elicit estrogenic responses to a different extend depending on the isomers present (Gabriel et al., 2008). In fish, binding to the estrogen receptor, induction of vitellogenin in vivo and in vitro, induction of estrogenic genes in cellular or yeast reporter assays has been observed by about 2-3 orders of magnitude above effect concentrations of the natural 17ß-estradiol (Scholz and Mayer, 2008; Scholz et al., 2013). The concentrations of NP and OP in the sediment fraction F6 referred to approximately $10 \%$ (NP) and $0.1 \%$ (OP) of their $\mathrm{EC}_{50}$ (Table 2). Given that the observed GFP induction rates were similar to those obtained for the individual compounds at their $\mathrm{EC}_{50}$, the concentrations of the analysed alkylphenols in F6 can only partially explain the observed estrogenic effect. However, other alkylphenols and xenoestrogens not targeted by the chemical analysis may have contributed to the observed GFP induction. Furthermore, it has been shown that compounds in mixtures produce significant estrogenic effect even when all individual compounds were present below their no-observed-effect-concentration (Silva et al., 2002). Hence, also levels of compounds below the detection limit could have contributed to the estrogenic effects of F6.

For F8, estrone was detected at concentrations approximately 10 to 30 fold above its $\mathrm{EC}_{50}$ concentrations (Table 2). Hence, the presence of estrone alone would explain the observed estrogenic effects. However, the observed fold change of induction was weaker than would have been expected for such a high concentrations (Brion et al., 2012; Petersen et al., 2013). Given that other weak estrogenic compounds (epi-androsterone and $\beta$-sitosterol) have been identified as well, it could be possible that the competitive binding of these and other nontargeted weaker agonists or antagonists may have repressed the estrogenic response to estrone.

In both estrogenic fractions, sterols were detected in substantial amounts. Only weak evidence is available for the estrogenic activity of coprostanol and cholesterol. Computational analysis of binding affinities to the estrogen receptor (Li and Gramatica, 2010) with the OECD QSAR Toolbox revealed strong estrogen receptor binding activity for both substances due to the cyclic molecular structure with a single non-impaired hydroxyl group (LMC, 2012). However, the predictive performance of the QSAR for estrogen binding activity appears to be limited (Mombelli, 2012). Experimental data do not support a potential estrogenic effect of cholesterol (Blair et al., 2000) and coprostanol (this study). Given the high hydrophobicity of coprostanol it is also unlikely to be bioavailable in dilutions of the solvent extracts used for the exposure of fish embryos. 


\section{Conclusion}

The $\operatorname{tg}($ cyp19a1b-GFP) zebrafish embryo model was shown to be compatible with the EDA approach to investigate the estrogenic activity of complex environmental samples. The transgenic strain allowed a simple detection of estrogenic effect without the need for sample processing. With automated procedures for image analysis that are likely to be available in the future, this could facilitate effective and fast quantification for even larger sample numbers such as typically obtained in EDA or environmental monitoring programs that consider an array of different samples. The observed estrogenic effects in sediment fractions could partially be explained by chemical analysis of selected compounds. In the most estrogenic fractions, alkylphenols and estrone, are likely to represent the major compounds contributing to the observed effects. The results confirmed that chemical analysis and effect assessment using transgenic fish embryos represent complementary approaches suitable for the assessment of (estrogenic) contaminations in environmental samples.

\section{Acknowledgement}

We would like to thank Margit Petre, Angela Sperreuter and Marion Heinrich for their great help in conducting the EDA. The work of Eva Fetter was supported by a scholarship of the German Federal Environmental Foundation (DBU).

\section{References}

Ali, S., van Mil, H.G., Richardson, M.K., 2011. Large-scale assessment of the zebrafish embryo as a possible predictive model in toxicity testing. PLoS One 6, e21076.

Andrási, N., Helenkár, A., Záray, G., Vasanits, A., Molnár-Perl, I., 2011. Derivatization and fragmentation pattern analysis of natural and synthetic steroids, as their trimethylsilyl (oxime) ether derivatives by gas chromatography mass spectrometry: Analysis of dissolved steroids in wastewater samples. Journal of Chromatography A 1218, 1878-1890.

Blair, R.M., Fang, H., Branham, W.S., Hass, B.S., Dial, S.L., Moland, C.L., Tong, W., Shi, L., Perkins, R., Sheehan, D.M., 2000. The estrogen receptor relative binding affinities of 188 natural and xenochemicals: structural diversity of ligands. Toxicological Sciences 54, 138-153.

Brack, W., 2003. Effect-directed analysis: a promising tool for the identification of organic toxicants in complex mixtures? Analytical and Bioanalytical Chemistry 377, 397-407.

Brion, F., Le Page, Y., Piccini, B., Cardoso, O., Tong, S.K., Chung, B.C., Kah, O., 2012. Screening estrogenic activities of chemicals or mixtures in vivo using transgenic (cyp19a1b-GFP) zebrafish embryos. PLoS One 7, e36069.

Chen, H., Hu, J., Yang, J., Wang, Y., Xu, H., Jiang, Q., Gong, Y., Gu, Y., Song, H., 2010. Generation of a fluorescent transgenic zebrafish for detection of environmental estrogens. Aquatic Toxicology 96, 53-61.

Clements, R.G., Nabholz, J.V., 1994. ECOSAR: a computer program and user's guide for estimating the ecotoxicity of industrial chemicals based on structure activity 
relationships, EPA-748-R-93-002. U.S. Environmental Protection Agency, Office of Pollution Prevention and Toxics 7403., Washington, DC.

Colborn, T., vom Saal, F.S., Soto, A.M., 1993. Developmental effects of endocrinedisrupting chemicals in wildlife and humans. Environmental Health Perspectives 101, 378384.

Creusot, N., Ait-Aissa, S., Tapie, N., Pardon, P., Brion, F., Sanchez, W., Thybaud, E., Porcher, J.M., Budzinski, H., 2014. Identification of synthetic steroids in river water downstream from pharmaceutical manufacture discharges based on a bioanalytical approach and passive sampling. Environmental Science and Technology 48, 3649-3657.

Creusot, N., Budzinski, H., Balaguer, P., Kinani, S., Porcher, J.M., Ait-Aissa, S., 2013. Effect-directed analysis of endocrine-disrupting compounds in multi-contaminated sediment: identification of novel ligands of estrogen and pregnane X receptors. Analytical and Bioanalytical Chemistry 405, 2553-2566.

EPA, 1994. Sample Clean-up with GPC, 3640. United States Environmental Protection Agency, United States.

Frische, T., Faust, M., Meyer, W., Backhaus, T., 2009. Toxic masking and synergistic modulation of the estrogenic activity of chemical mixtures in a yeast estrogen screen (YES). Environmental Science and Pollution Research International 16, 593-603.

Frye, C.A., Bo, E., Calamandrei, G., Calza, L., Dessi-Fulgheri, F., Fernandez, M., Fusani, L., Kah, O., Kajta, M., Le Page, Y., Patisaul, H.B., Venerosi, A., Wojtowicz, A.K., Panzica, G.C., 2012. Endocrine disrupters: a review of some sources, effects, and mechanisms of actions on behaviour and neuroendocrine systems. Journal of Neuroendocrinology 24, 144159.

Gabriel, F.L., Routledge, E.J., Heidlberger, A., Rentsch, D., Guenther, K., Giger, W., Sumpter, J.P., Kohler, H.P., 2008. Isomer-specific degradation and endocrine disrupting activity of nonylphenols. Environmental Science and Technology 42, 6399-6408.

Grund, S., Higley, E., Schonenberger, R., Suter, M.J., Giesy, J.P., Braunbeck, T., Hecker, M., Hollert, H., 2011. The endocrine disrupting potential of sediments from the Upper Danube River (Germany) as revealed by in vitro bioassays and chemical analysis. Environmental Science and Pollution Research International 18, 446-460.

Hollert, H., Durr, M., Holtey-Weber, R., Islinger, M., Brack, W., Farber, H., Erdinger, L., Braunbeck, T., 2005. Endocrine disruption of water and sediment extracts in a non-radioactive dot blot/RNAse protection-assay using isolated hepatocytes of rainbow trout. Environmental Science and Pollution Research International 12, 347-360.

Ji, C., Jin, X., He, J., Yin, Z., 2012. Use of TSHbeta:EGFP transgenic zebrafish as a rapid in vivo model for assessing thyroid-disrupting chemicals. Toxicology and Applied Pharmacology 262, 149-155.

Jung, E.M., An, B.S., Yang, H., Choi, K.C., Jeung, E.B., 2012. Biomarker genes for detecting estrogenic activity of endocrine disruptors via estrogen receptors. International Journal of Environmental Research and Public Health 9, 698-711.

Jurajda, P., Adamek, Z., Janac, M., Valova, Z., 2010. Longitudinal patterns in fish and macrozoobenthos assemblages reflect degradation of water quality and physical habitat in the Bilina river basin. Czech Journal of Animal Science 55, 123-136.

Kidd, K.A., Blanchfield, P.J., Mills, K.H., Palace, V.P., Evans, R.E., Lazorchak, J.M., Flick, R.W., 2007. Collapse of a fish population after exposure to a synthetic estrogen. Proceedings of the National Academy of Sciences of the United States of America 104, 88978901.

Knöbel, M., Busser, F.J., Rico-Rico, A., Kramer, N.I., Hermens, J.L., Hafner, C., Tanneberger, K., Schirmer, K., Scholz, S., 2012. Predicting adult fish acute lethality with the zebrafish embryo: relevance of test duration, endpoints, compound properties, and exposure concentration analysis. Environmental Science and Technology 46, 9690-9700. 
Le Page, Y., Menuet, A., Kah, O., Pakdel, F., 2008. Characterization of a cis-acting element involved in cell-specific expression of the zebrafish brain aromatase gene. Molecular Reproduction and Development 75, 1549-1557.

Legler, J., Broekhof, J.L.M., Brouwer, A., Lanser, P.H., Murk, A.J., Van der Saag, P.T., Vethaak, A.D., Wester, P., Zivkovic, D., Van der Burg, B., 2000. A novel in vivo bioassay for (xeno-)estrogens using transgenic zebrafish. Environmental Science and Technology 34, 4439-4444.

Legler, J., van Velzen, M., Cenijn, P.H., Houtman, C.J., Lamoree, M.H., Wegener, J.W., 2011. Effect-directed analysis of municipal landfill soil reveals novel developmental toxicants in the zebrafish Danio rerio. Environmental Science and Technology 45, 8552-8558.

Li, J., Gramatica, P., 2010. QSAR classification of estrogen receptor binders and prescreening of potential pleiotropic EDCs. SAR and QSAR in Environmental Research 21, 657669.

LMC, 2012. OECD QSAR Application Toolbox V3.0. The software available from http://www.qsartoolbox.org.

Maes, J., Verlooy, L., Buenafe, O.E., de Witte, P.A., Esguerra, C.V., Crawford, A.D., 2012. Evaluation of 14 organic solvents and carriers for screening applications in zebrafish embryos and larvae. PLoS One 7, e43850.

Maffini, M.V., Rubin, B.S., Sonnenschein, C., Soto, A.M., 2006. Endocrine disruptors and reproductive health: the case of bisphenol-A. Molecular and Cellular Endocrinology 254-255, 179-186.

Marvin, C., Coakley, J., Mayer, T., Brown, M., Thiessen, L., 2001. Application of faecal sterol ratios in sediments and effluents as source tracers. Water Quality Research Journal of Canada 36, 781-792.

Menuet, A., Pellegrini, E., Brion, F., Gueguen, M.M., Anglade, I., Pakdel, F., Kah, O., 2005. Expression and estrogen-dependent regulation of the zebrafish brain aromatase gene. The Journal of Comparative Neurology 485, 304-320.

Mombelli, E., 2012. Evaluation of the OECD (Q)SAR Application Toolbox for the profiling of estrogen receptor binding affinities. SAR and QSAR in Environmental Research 23, 37-57.

Mouriec, K., Gueguen, M.M., Manuel, C., Percevault, F., Thieulant, M.L., Pakdel, F., Kah, O., 2009. Androgens upregulate cyp19a1b (aromatase B) gene expression in the brain of zebrafish (Danio rerio) through estrogen receptors. Biology of Reproduction 80, 889896.

Nagel, R., 2002. DarT: The embryo test with the Zebrafish Danio rerio--a general model in ecotoxicology and toxicology. ALTEX 19 Suppl 1, 38-48.

Nakada, N., Tanishima, T., Shinohara, H., Kiri, K., Takada, H., 2006. Pharmaceutical chemicals and endocrine disrupters in municipal wastewater in Tokyo and their removal during activated sludge treatment. Water Research 40, 3297-3303.

OECD, 2009. Fish Short Term Reproduction Assay, No 229. OECD Guideline for the Testing of Chemicals. Organization of Economic Cooperation and Development, Paris.

Orendt, C., Wolfram, G., Adamek, Z., Jurajda, P., Schmitt-Jansen, M., 2012. The response of macroinvertebrate community taxa and functional groups to pollution along a heavily impacted river in Central Europe (Bilina River, Czech Republic). Biologia 67, 180199.

Pardo-Martin, C., Chang, T.Y., Koo, B.K., Gilleland, C.L., Wasserman, S.C., Yanik, M.F., 2010. High-throughput in vivo vertebrate screening. Nature Methods 7, 634-636.

Petersen, K., Fetter, E., Kah, O., Brion, F., Scholz, S., Tollefsen, K.E., 2013. Transgenic (cyp19a1b-GFP) zebrafish embryos as a tool for assessing combined effects of oestrogenic chemicals. Aquatic Toxicology 138-139, 88-97. 
Pfaffl, M.W., 2001. A new mathematical model for relative quantification in realtime RT-PCR. Nucleic Acids Research 29, e45.

Quesada-Garcia, A., Valdehita, A., Torrent, F., Villarroel, M., Hernando, M.D., Navas, J.M., 2013. Use of fish farms to assess river contamination: combining biomarker responses, active biomonitoring, and chemical analysis. Aquatic Toxicology 140-141, 439448.

Racz, L., Goel, R.K., 2010. Fate and removal of estrogens in municipal wastewater. Journal of Environmental Monitoring 12, 58-70.

Rastall, A.C., Getting, D., Goddard, J., Roberts, D.R., Erdinger, L., 2006. A biomimetic approach to the detection and identification of estrogen receptor agonists in surface waters using semipermeable membrane devices (SPMDs) and bioassay-directed chemical analysis. Environmental Science and Pollution Research International 13, 256-267.

Schmitt, C., Balaam, J., Leonards, P., Brix, R., Streck, G., Tuikka, A., Bervoets, L., Brack, W., van Hattum, B., Meire, P., de Deckere, E., 2010. Characterizing field sediments from three European river basins with special emphasis on endocrine effects - A recommendation for Potamopyrgus antipodarum as test organism. Chemosphere 80, 13-19.

Schmitt, S., Reifferscheid, G., Claus, E., Schlüsener, M., Buchinger, S., 2012. Effect directed analysis and mixture effects of estrogenic compounds in a sediment of the river Elbe. Environmental Science and Pollution Research International 19, 3350-3361.

Scholz, S., 2013. Zebrafish embryos as an alternative model for screening of druginduced organ toxicity. Archives of Toxicology 87, 767-769.

Scholz, S., Klüver, N., 2009. Effects of endocrine disrupters on sexual, gonadal development in fish. Sexual Development 3, 136-151.

Scholz, S., Mayer, I., 2008. Molecular biomarkers of endocrine disruption in small model fish. Molecular and Cellular Endocrinology 293, 57-70.

Scholz, S., Renner, P., Belanger, S.E., Busquet, F., Davi, R., Demeneix, B.A., Denny, J.S., Leonard, M., McMaster, M.E., Villeneuve, D.L., Embry, M.R., 2013. Alternatives to in vivo tests to detect endocrine disrupting chemicals (EDCs) in fish and amphibians--screening for estrogen, androgen and thyroid hormone disruption. Critical Reviews in Toxicology 43, 45-72.

Silva, E., Rajapakse, N., Kortenkamp, A., 2002. Something from "nothing"--eight weak estrogenic chemicals combined at concentrations below NOECs produce significant mixture effects. Environmental Science and Technology 36, 1751-1756.

Strähle, U., Scholz, S., Geisler, R., Greiner, P., Hollert, H., Rastegar, S., Schumacher, A., Selderslaghs, I., Weiss, C., Witters, H., Braunbeck, T., 2012. Zebrafish embryos as an alternative to animal experiments--a commentary on the definition of the onset of protected life stages in animal welfare regulations. Reproductive Toxicology 33, 128-132.

Tong, S.K., Mouriec, K., Kuo, M.W., Pellegrini, E., Gueguen, M.M., Brion, F., Kah, O., Chung, B.C., 2009. A cyp19a1b-gfp (aromatase B) transgenic zebrafish line that expresses GFP in radial glial cells. Genesis 47, 67-73.

USEPA, 2009. Fish short-term reproduction assay, Endocrine disruptor screening program test guidelines, OPPTS 890.1350. United States Environmental Protection Agency, Washington, D.C.

Vosges, M., Le Page, Y., Chung, B.C., Combarnous, Y., Porcher, J.M., Kah, O., Brion, F., 2010. 17alpha-ethinylestradiol disrupts the ontogeny of the forebrain GnRH system and the expression of brain aromatase during early development of zebrafish. Aquatic Toxicology 99, 479-491.

Wang, L., Ying, G.G., Chen, F., Zhang, L.J., Zhao, J.L., Lai, H.J., Chen, Z.F., Tao, R., 2012. Monitoring of selected estrogenic compounds and estrogenic activity in surface water and sediment of the Yellow River in China using combined chemical and biological tools. Environmental Pollution 165, 241-249. 
Wang, R.L., Biales, A., Bencic, D., Lattier, D., Kostich, M., Villeneuve, D., Ankley, G.T., Lazorchak, J., Toth, G., 2008. DNA microarray application in ecotoxicology: experimental design, microarray scanning, and factors affecting transcriptional profiles in a small fish species. Environmental Toxicology and Chemistry 27, 652-663.

Westerfield, M., 1993. The zebrafish book : a guide for the laboratory use of zebrafish (Brachydanio rerio). Univ. of Oregon Press, Eugene., Oregon, United States.

Yang, Y.Y., Gray, J.L., Furlong, E.T., Davis, J.G., Revello, R.C., Borch, T., 2012. Steroid hormone runoff from agricultural test plots applied with municipal biosolids. Environmental Science and Technology 46, 2746-2754. 
Fig. 1. Flowchart describing the effect-directed analysis of the Bilina river sediment sample. After each step of sample preparation an aliquot of the sample was removed and analysed by $\operatorname{tg}$ (cyp19a1b-GFP) zebrafish embryos. Only for concentrations for which $\leq 20 \%$ of all embryos showed lethal or sublethal effects (malformations, oedema), the GFP fluorescence was quantified. 
Fig. 2. Induction of GFP in embryos exposed to sediment extract after pressurized liquid extraction (PLE, A) and after clean-up with gel permeation chromatography (GPC, B). DMSO and $50 \mathrm{pM}$ ethinylestradiol (EE2) represent negative and positive controls, respectively. Percentages refer to stock solution of extracts: $0.73 \mathrm{~g}$ sediment equivalent $/ \mathrm{mL}$ for PLE, $4.89 \mathrm{~g}$ sediment equivalent $/ \mathrm{mL}$ for GPC, respectively. GFP expression was quantified in one experiment with ten embryos for each concentration. (Bars refer to mean \pm standard deviation, $\mathrm{n}=10$ ). 
Fig. 3. Induction of GFP and relative expression of cyp19a1b gene in embryos exposed to the normal phase HPLC fractions (F1-F10) of a sediment extract from the river Bilina in the Czech Republic. Percentages refer to dilutions of fractions representing $33 \mathrm{~g}$ sediment equivalent $/ \mathrm{mL}$. GFP was quantified by image analysis. Gene expression of cyp19a1b was measured by qRT-PCR. DMSO (0.05\% v/v) and $50 \mathrm{pM}$ ethinylestradiol (EE2) represent negative and positive controls, respectively.

GFP induction was quantified using three independent replicates with ten embryos for each concentration. (Bars refer to mean \pm standard deviation, $\mathrm{n}=3 . * * \mathrm{p}<0.01 ; * * * \mathrm{p}<0.001$ ). qRT-PCR was performed in one replicate only (black bars). 


\section{Highlights}

Transgenic zebrafish embryos were applied for the first time in EDA

Clean-up and fractionation increased the concentration of SEQ applicable in biotests Two estrogenic fractions were identified using the $\operatorname{tg}($ cyp19a1b-GFP) bioassay

Alkylphenols and estrone concentrations partially explained the estrogenic effects 
Table 1. Results of the GC-MS analysis on the fractionated sediment sample. Analysis was conducted in two steps with different sensitivity and selectivity. Italic numbers represent the data of the second analysis. Empty fields represent samples with concentrations below the detections limit. Concentrations are given in $\mathrm{ng} / \mathrm{g}$ sediment equivalent. For concentrations per volume of sediment extract refer to Table 2 .

\begin{tabular}{|c|c|c|c|c|c|c|c|c|c|c|c|c|}
\hline $\begin{array}{l}\text { Compounds (ng/g } \\
\text { sediment equivalent) }\end{array}$ & $\begin{array}{c}\mathbf{L o Q} \\
(\mathbf{1})^{*}\end{array}$ & $\begin{array}{r}\text { LoQ } \\
(2)^{*}\end{array}$ & F1 & F2 & F3 & F4 & F5 & F6 & F7 & F8 & F9 & F10 \\
\hline \multicolumn{13}{|l|}{$\begin{array}{l}\text { Alkyphenols } \\
\text { and bisphenols }\end{array}$} \\
\hline Bisphenol A & 0.5 & 0.5 & & & & 0.9 & 1.1 & & 0.6 & & 1.1 & \\
\hline Bisphenol F & 2 & 0.5 & & & & & & & & & & \\
\hline Bisphenol S & n.a. & 0.5 & & & & & & & & & & \\
\hline 4-Nonylphenol & 50 & 5 & & & & & & 260 & 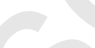 & & & \\
\hline 4-tert-Octylphenol & 5 & 0.1 & & & & & & 7.1 & 2 & & & \\
\hline \multicolumn{13}{|l|}{ Steroids } \\
\hline 17 $\alpha$-Estradiol & 10 & 2.5 & & & & & & & 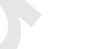 & & & \\
\hline $17 \alpha$-Ethinylestradiol & 20 & 3 & & & & & & & & & & \\
\hline 17ß-Estradiol & 10 & 2.5 & & & & & & & & & & \\
\hline Androstendione & n.a. & 8 & & & & & & & & & & \\
\hline Androsterone & n.a. & 5 & & & & & & & & & & \\
\hline Cholesterol & 20 & 10 & & & & & & & 17800 & 830 & 52.0 & 27.0 \\
\hline Coprostanol & 2 & 1 & & & & 7.4 & 17.0 & 63100 & 1659 & 57.4 & 31.5 & 3.1 \\
\hline Desogestrel & 50 & n.a. & & & & & & & & & & \\
\hline Epi-androsterone & n.a. & 5 & & & & $\nabla$ & & & & 10 & 11 & \\
\hline Estriol & 20 & 5 & & & & & & & & & & \\
\hline Estrone & 20 & 5 & & & & & & & & 699 & & \\
\hline Levonorgestrel & 150 & n.a. & & & & & & & & & & \\
\hline Mestranol & 10 & 5 & & & & & & & & & & \\
\hline Norethindrone & 20 & 5 & & & & & & & & & & \\
\hline Norgestimate & 1200 & n.a. & & & & & & & & & & \\
\hline Progesterone & 50 & 5 & & & & & & & & & & \\
\hline Testosterone & n.a. & 5 & & & & & & & & & & \\
\hline$\beta$-Sitosterol & n.a. & 20 & 39 & & & 27 & 43 & & 11150 & 875 & 83 & \\
\hline \multicolumn{13}{|l|}{ Musks } \\
\hline Amberonne & 20 & n.a. & & & & 18 & & & & & & \\
\hline Ambrettolide & 200 & n.a. & & & & & & & & & & \\
\hline Benzophenone & 10 & n.a. & & & & 16 & 18 & & & & & \\
\hline Cashmeran & 50 & n.a. & & & & & & & & & & \\
\hline Celestolide & 20 & n.a. & & & & & & & & & & \\
\hline Habanolide & 160 & n.a. & & & & & & & & & & \\
\hline Methyl cedryl ketone & 50 & n.a. & & & & & 69 & & & & & \\
\hline Musk ketone & 20 & n.a. & & & & & & & & & & \\
\hline Musk xylene & 20 & n.a. & & & & & & & & & & \\
\hline Phantolide & 10 & n.a. & & & & & & & & & & \\
\hline Tonalide & 20 & n.a. & & & & 39 & 47 & & & & & \\
\hline Velvione & 150 & n.a. & & & & & & & & & & \\
\hline
\end{tabular}

*(1) and (2) refer to the first and second analytical measurement (details are given in the Material and Method section.

n.a. not analysed. 
Table 2. Comparison of the concentrations of compounds found in fractions F6 and F8 with their $\mathrm{EC}_{50}$ (n.d. $=$ not detected, n.e. $=$ compound does not exhibit estrogenic effects).

\begin{tabular}{|c|c|c|c|}
\hline \multirow[t]{2}{*}{ Candidate estrogens detected in the fractions } & \multirow[t]{2}{*}{$\mathbf{E C}_{50}(\mathrm{nM})$} & \multicolumn{2}{|c|}{$\begin{array}{l}\text { Concentration }(\mathrm{nM}) \text { in the } \\
\text { exposure medium }\end{array}$} \\
\hline & & F6 & F8 \\
\hline 4-nonylphenol & $255.5-406^{\mathrm{a}}$ & 19.46 & n.d. \\
\hline 4-tert-Octylphenol & $595-620^{\mathrm{a}}$ & 0.57 & n.d. \\
\hline Estrone & $1.3-4.4^{\mathrm{a}}$ & n.d. & 42.66 \\
\hline Epi-androsterone ( $5 \alpha$-androstane- $3 \beta, 17 \beta$-diol) & $(35.4-1031)^{b}$ & n.d. & 0.55 \\
\hline$\beta$-sitosterol & $\sim 2500^{\mathrm{c}}$ & n.d. & 34.81 \\
\hline Cholesterol & n.e. $^{d}$ & n.d. & 35.40 \\
\hline Coprostanol & n.e. ${ }^{\mathrm{e}}$ & $<<2679^{f}$ & $<<2.44^{\mathrm{f}}$ \\
\hline
\end{tabular}

${ }^{a}$ The indicated range of $\mathrm{EC}_{50}$ values is based on data from Brion et al. (2012), Petersen et al. (2013) and/or this study (Fig. S1).

${ }^{\mathrm{b}} \mathrm{No} \mathrm{EC}_{50}$ values of estrogenic effects in fish embryos are available for this androgen. The indicated range refers to the $\mathrm{EC}_{50}$ of the androgens testosterone, 17- $\alpha$-methyltestosterone, dihydrotestosterone, 17 $\beta$-trenbolone and $\mathrm{R} 1881$ in $\operatorname{tg}$ (cyp19a1b-GFP) embryos (Brion et al. 2012). The relative binding affinity of epi-androsterone to the estrogen receptor (based on rat uterine cytosol preparations) is $0.12 \%$ (to estradiol) and $1.6 \%$ of estrone (Blair et al. 2000).

${ }^{c}$ No values for fish embryos available. The comparison of concentration-dependent vitellogenin induction with 4-nonylphenol and $\beta$-sitosterol in rainbow trout hepatocytes suggests an appr. 10 fold weaker estrogenic potency for $\beta$-sitosterol.

${ }^{\mathrm{d}}$ Studies with rat estrogen receptor (uterine cytosol preparations) did not indicate any binding affinity for cholesterol (Blair et al. 2000).

${ }^{\mathrm{e}}$ No estrogenic effect detected in fish embryos (this study).

${ }^{\mathrm{f}}$ Coprostanol has an estimated $\log K_{O W}$ of 8.8 and a water solubility of $0.23 \mathrm{nmol} / \mathrm{L}$ (predicted with ECOSARClements and Nabholz, 1994). Hence, the calculated concentrations of the diluted fractions (based on chemical analysis of solvent extracts) overestimate the bioavailable concentrations. 


\section{Pressurized Liquid Extraction: $50 \mathrm{~g}$ sediment}

\begin{tabular}{|l|l|}
$\begin{array}{ll}\text { Bioassay: } 1.1 \mathrm{~g} \text { sediment equivalent } \\
\text { dissolved in } 1.5 \mathrm{~mL} \text { DMSO }\end{array}$ & $\begin{array}{l}\text { Toxicity tested for: } \\
0.01,0.1,1 \%\end{array}$ \\
$\begin{array}{ll}\text { Highest tolerable concentration: } 0.73 \\
\text { g sediment equivalent } / \mathrm{L}\end{array}$ & $\begin{array}{l}\text { Selected for screening of } \\
\text { estrogenic activity: } 0.01, \\
0.1 \%\end{array}$ \\
\hline
\end{tabular}

\section{Gel Permeation Chromatography:} $48.9 \mathrm{~g}$ sediment equivalent

\begin{tabular}{|l|}
\hline $\begin{array}{l}\text { Bioassay: } 4.89 \mathrm{~g} \text { sediment eq } \\
\text { dissolved in } 1 \mathrm{~mL} \text { DMSO }\end{array}$ \\
$\begin{array}{l}\text { Highest tolerable concentration: } \\
\text { g sediment equivalent } / \mathrm{L}\end{array}$ \\
$\begin{array}{l}\text { Normal Phase-HPLC: } \\
44.01 \mathrm{~g} \text { sediment equivalent }\end{array}$ \\
\hline
\end{tabular}

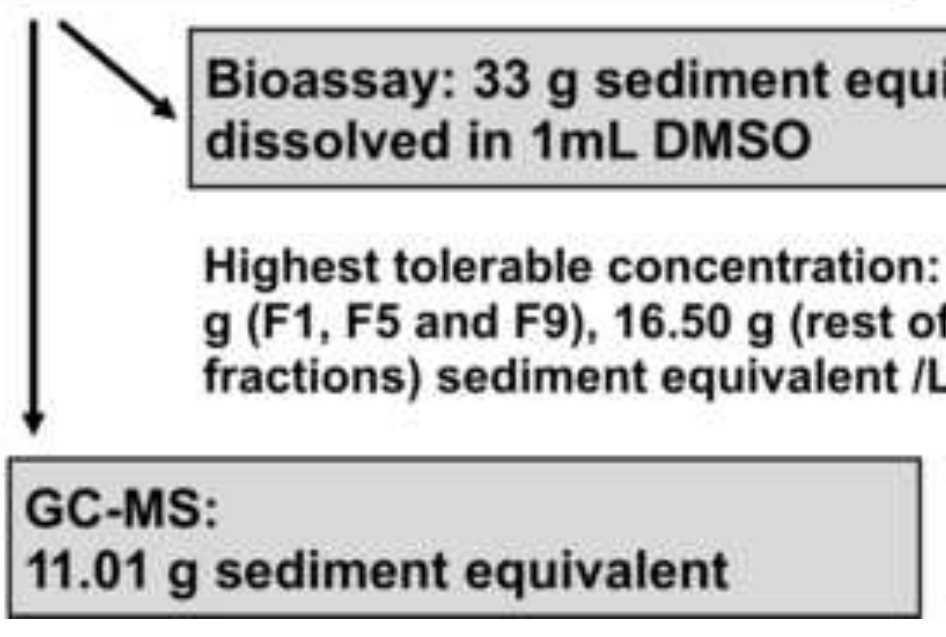

Toxicity tested for: $0.01,0.05,0.1,0.5 \%$

Selected for screening of estrogenic activity: $0.01 \%$ for F1, F5 and F9; $0.05 \%$ for the rest of the fractions
Selected for screening of
estrogenic activity: 0.01 ,

Selected for screening of
estrogenic activity: 0.01 , $0.05 \%$

Toxicity tested for: $0.01,0.05,0.1,0.5,1 \%$ 

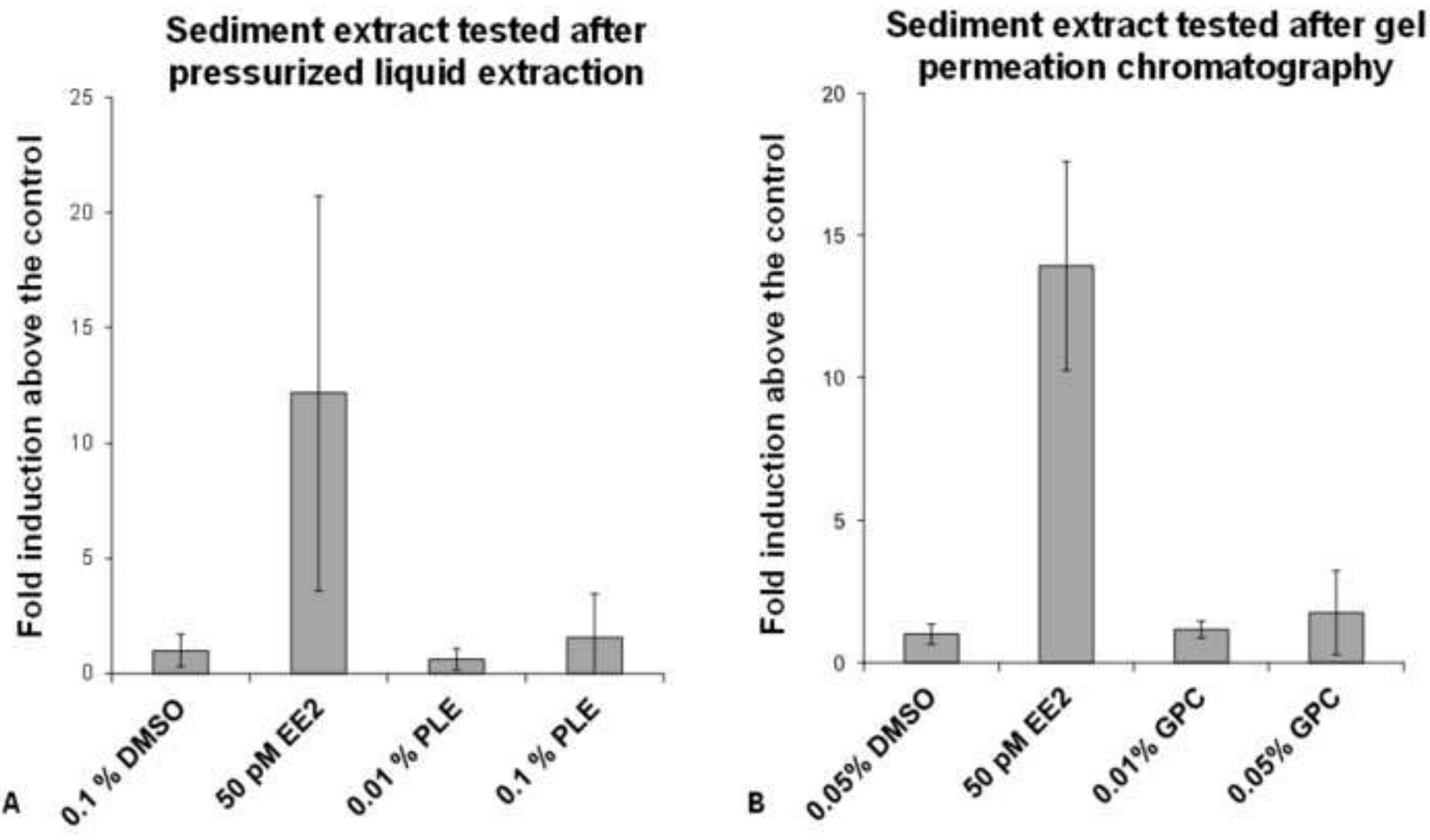


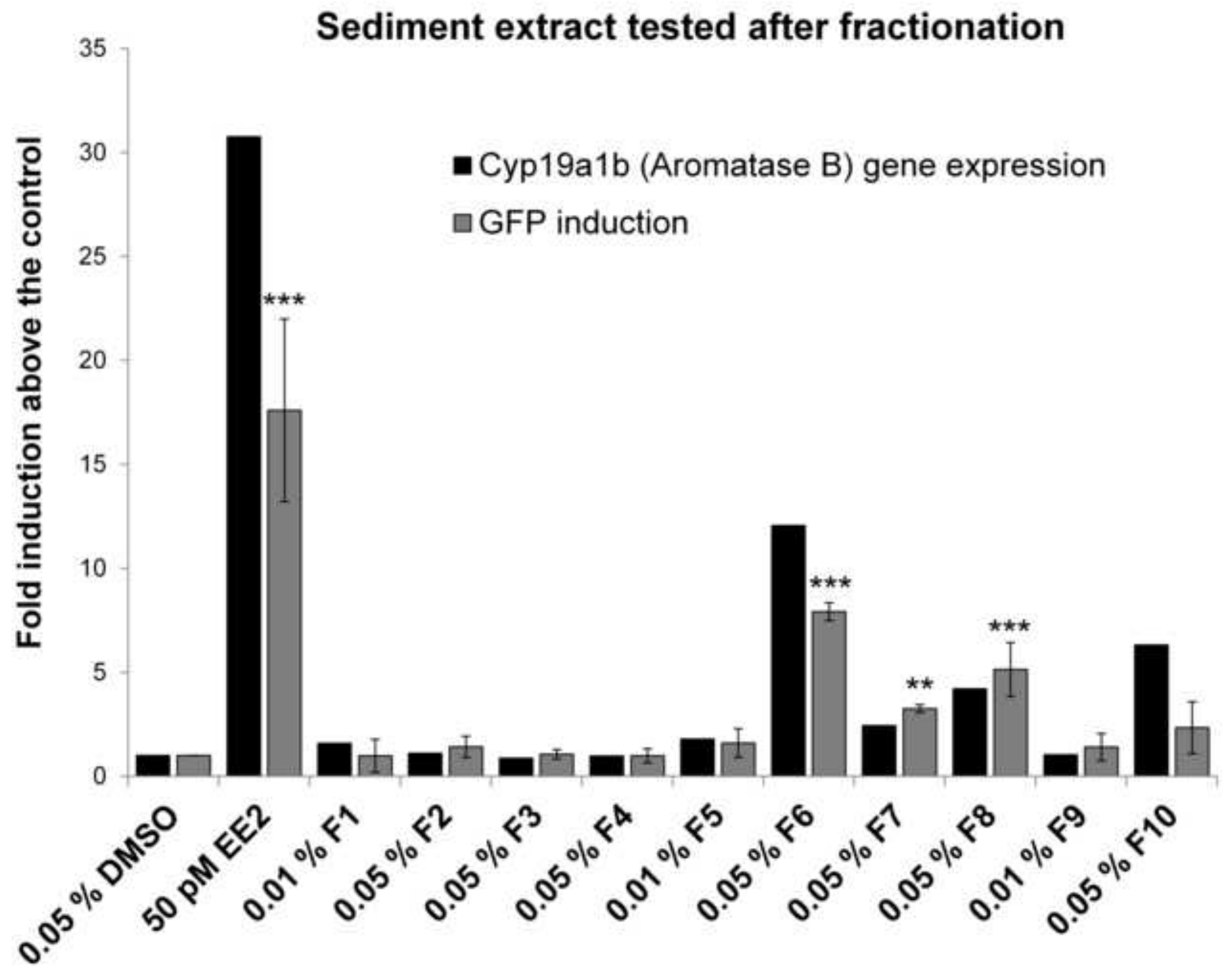

